\title{
LA TERCERA PERSONA DESDE LA FOCALIZACIÓN INTERNA: SU EQUIVALENCIA CON LA NARRACIÓN EN PRIMERA PERSONA
}

Pilar Rubio Montaner

Universidad de Valladolid

INTRODUCCIÓN: A FAVOR DE UNA NARRACIÓN DESDE EL PERSONAJE

En los relatos caracterizados por la omnisciencia, el punto de vista ajeno y poderoso del agente focalizador externo se traduce en una voz del mismo tipo: externa y poderosa. «El narrador omnisciente, a la manera tradicional, de tono épico, diríamos, utiliza la tercera persona para narrar desde fuera los sucesos novelescos, pero sin prohibirse a sí mismo - a su voz de narrador- el comentar, adelantar acontecimientos, el caracterizar moralmente a los personajes, etc. El narrador está en todas partes, todo lo sabe, actúa como un dios frente a sus criaturas, y procura hacérselo ver así al lectorn' ${ }^{1}$. La narrativa tradicional utiliza esta fórmula casi siempre. El narrador-focalizador sabe más que los propios personajes: ve a través de las paredes de la casa lo mismo que a través del cráneo de sus héroes, se traslada sin dificultad en el espacio y en el tiempo (conoce el pasado de la historia como conoce el presente, o adelanta el futuro)...Más aún, no se limita a los acontecimientos de la historia sino que la decora, la rellena, la extiende con descripciones ajenas a las peripecias del personaje. Mediante sobreinformaciones, el narrador transmite elementos que el focalizador externo se p. 125.

' M. Baquero Goyanes, Estructuras de la novela actual, Barcelona, Planeta, 3." ed., 1975, 
permite observar más allá de los acontecimientos fabulados. Chatman analiza, en este sentido, una serie de rasgos propios del narrador omnisciente: explicaciones que se asientan sobre una base moral externa al relato (juicios); comparaciones de acontecimientos existentes en la historia con acontecimientos reales del universo no fabulado (generalizaciones); valoraciones acerca de algo, en términos de la historia misma, sin ir fuera de ella (interpretaciones) ${ }^{2}$. Es decir, mediante lo que Genette denomina metalepsis, como «intrusion du narrateur ou du narrataire extradiégétique dans l'univers diégétique ${ }^{3}$, se vierten en el texto reflexiones que en absoluto pertenecen al universo fabulado. En resumen: el narrador omnisciente, partiendo de una focalización privilegiada que permite contemplar pasado, presente y futuro del personaje, se erige en depositario de la verdad y cuenta la historia emitiendo sobre ella juicios infalibles. Este narrador es quien tiene, siempre, la última palabra.

Nos encontramos así ante una especie de superhéroe que maneja los hilos de una historia (tanto en la focalización como en la voz) en la que los personajes esperan, como entre bastidores, para aparecer o desaparecer, a merced del misterioso ser que los presenta, juzga... a merced del intermediario que se mueve cómodamente por la escena, de cara al espectadorlector, dando la espalda a sus propios personajes. La narrativa decimonónica está considerada como el ejemplo cumbre de este tipo de enfoque tradicional, a la hora de seleccionar el punto de vista y la voz para abordar el discurso. El omnisciente externo es un sujeto distanciado del mundo del relato que dice al lector, implícita o explícitamente: «Aquí está la historia, ahí tú lector; yo la conozco, la valoro, la juzgo incluso y te la transmito". El narrador se convierte, así, en un intermediario manipulador, y los tres elementos de la cadena historia-narrador-lector se dan como bloques aislados: no existen más interferencias entre ellos que los posibles juicios de valor del omnisciente sobre los personajes o situaciones (juicios que indican más aún este aislamiento), o la simpatía/antipatía del lector hacia dichos personajes (animosidad derivada, a su vez, de esas valoraciones emitidas por el manipulador de la historia).

La reacción, en la escritura, contra esta potestad omnisciente se concentra, particularmente, en la visión antinatural y artificiosa del sabio focalizador-narrador alejado del universo de la historia. En el siglo Xx va a potenciarse como consecuencia, y por diferentes caminos, una visión más acorde con los modos de percepción humana. Uno de estos caminos es la narración desde el punto de vista del personaje.

Con la narración desde esta perspectiva, lo narrado parece más humano,

2 Ver, para estos conceptos, Seymour Chatman, Story and Discourse: Narrative Structure in Fiction and Film, Londres, Cornell University Press, Ithaca, 1983, pp. 237-238.

${ }^{3}$ G. Genette, Figures III. Paris, Seuil, 1972, p. 244. 
más verosímil; ya no estamos ante una historia que alguien cuenta que sucedió, sino ante una historia que está sucediendo, vivida en ese momento por el personaje. Con la narración desde la perspectiva interna ya no se "decreta», sólo se «muestra» el mundo como lo ven sus héroes.

En el siglo XIX se va empleando cada vez más este artificio de presentar la historia a través de sus proyecciones en la conciencia del personaje. Este procedimiento, sistematizado por Henry James, se convertirá en casi la regla obligada de la narrativa del siglo XX. En James el recurso es consciente y a él aludió el novelista en varios de sus prefacios. James pretende mostrar a sus personajes como contemplándose en un juego de espejos: la narración nos ofrecerá a unos personajes a través de la conciencia de otros. Es la adopción del punto de vista controlado, el punto de vista interno, situado en el espíritu del personaje. Los prefacios de Henry James han llegado a ser una obra clásica en la crítica anglo-sajona. En ellos se establece ya un corpus teórico fundamentado en la actividad literaria ${ }^{4}$.

Nos encontramos ante la dicotomía telling y showing, planteada por Lubbock en The Craft of Fiction ${ }^{5}$, en la cual se argumenta cómo la novela deberá huir de la influencia del narrador, cómo deberá mostrar al lector los acontecimientos sin mediación alguna.

Los relatos concebidos de esta manera nos darán las versiones del «parecer» sin pretender construir una historia única, verdadera; y la búsqueda del punto de vista apropiado será una de las, a veces obsesivas, metas del autor cuando se plantea abordar la narración. Marguerite Yourcenar en sus notas a las Mémoires d'Hadrien declara que si decidió escribirlas en primera persona fue para evitar, en lo posible, cualquier intermediario: Adriano podía hablar de su vida con más firmeza y más sutileza que la propia autora. La preocupación de Max Frisch al escribir Der Mensch erscheint in Holozäm es cómo contar una historia de soledad (la del señor Geiser) desde el punto de vista de la absoluta soledad; no quiere Frisch hacerlo en el estilo de Thomas Mann porque de este modo el personaje no estará solo, siempre estará el Mann «sabio» detrás de él. Como ha escrito Kayser: «Tout se passe comme si l'échelle des valeurs avait été renversée, comme si les romanciers modernes -et plus d'un a effectivement exprimé cette opinion- considéraient le narrateur objetif [hace referencia al omnisciente] comme une convention dépassée, fausse et antipoétique, le changement de la perspective, le récit à la première personne ou d'un point de vue personnel étant, au contraire, la solution juste et poétiquen ${ }^{6}$. Tan obsesiva es la intención de evitar la fórmula tradicional omnisciente, que llegamos a encontrar la búsqueda de la verosimilitud, mediante el punto de vista desde el personaje,

4 Henry James, El futuro de la novela, Madrid, Taurus, 1975.

s Percy Lubbock, The Craft of Fiction, Nueva York, The Viking Press, 1963.

-Wolfgang KAYSER, «Qui raconte le roman?», en Poétique, 4, 1970, p. 500. 
incluso en historias que son absolutamente fantásticas (en cuanto a su falta de relación con el universo real, en cuanto a su imposibilidad de realización en el universo no ficticio). Il cavaliere inesistente de Italo Calvino comienza mediante una voz externa que va de unos personajes a otros, narra lo que pertenece a la conciencia de todos, y elabora sus propios juicios; pero a las pocas páginas aparece la justificación de ese narrador que creíamos externo y omnisciente y no molestaba debido al carácter fantástico de la historia: la voz de un personaje implicado en ella se va intercalando de vez en cuando en el texto, para recordarnos que cuenta lo que ha llegado a conocer más lo que se imagina.

Frente a la amplia perspectiva de un omnisciente, el narrador de nuestro siglo parte de una focalización angosta y subjetiva, de una perspectiva restringida a las experiencias de un individuo tan limitado como el ser humano. Pero la narración desde la perspectiva interna puede presentarse, bien mediante la voz del propio personaje implicado en la historia (es el relato que utiliza normalmente la primera persona), bien mediante la voz del narrador no implicado en la historia (en este caso será la tercera persona).

Algunas tipologias anteriores a Genette (a pesar de no precisar entre focalización y voz, de confundir ambas categorías o ceñirse exclusivamente al punto de vista) distinguen entre las posibilidades de primera y tercera persona para el punto de vista interno. Stanzel, por ejemplo, diferencia entre la situación en que el narrador es uno de los personajes (la Ich Erzählsituation) y el relato en tercera persona según el punto de vista de un personaje (la personale Erzählsituation)". Friedman distingue entre el "yo», como testigo o protagonista; la "omnisciencia multi-selectiva», cuando la historia es presentada tal y como se refleja en el espíritu de los personajes, pero mediante un narrador externo; y la "omnisciencia selectiva», si la historia está limitada al punto de vista de un solo personaje, aunque sea contada en tercera persona ${ }^{8}$. Todorov, matizando con mínimas modificaciones la tipología de Pouillon', precisa que la narración desde la visión «con» $(\mathbf{N}=\mathbf{P})$ «puede hacerse en primera persona (lo que justifica este procedimiento) o en tercera persona, pero siempre según la visión que tiene de los acontecimientos un mismo personaje» ${ }^{10}$.

Ahora bien, esta segunda fórmula de la tercera persona no es tan diferente de la primera persona, como suele presentarse en algunas tipologías, sino que deberían analizarse ambas como equivalentes (eso sí, precisando voz y focalización) puesto que tanto la primera persona como la tercera

' STANZEL, Die typischen Erzählsituationen in Roman, Vienne-Stuttgart 1955.

- Norman Friedman, "Point of view in Fiction: The Development of a Critical Concept", en Proceedings of the Modern Language Association of America, 70, I, 1955, pp. 1160-1184.

9 J. Pouillon, Temps et Roman, Paris, Gallimard, 1946.

10 T. Todorov, Literatura y significación, Barcelona, Planeta, 1971, p. 100. 
desde la perspectiva interna, van a tener una misma función narrativa: la elaboración del relato desde la historia misma. Y, ambas, debido a esta misma función, van a presentar iguales manifestaciones en el discurso.

Para ejemplificar esta afirmación, que será el centro de nuestro estudio, y analizar las consecuencias que en el discurso presenta la tercera persona desde la focalización interna, tomaremos los relatos de uno de los autores más consecuentes en la elaboración de la historia desde el punto de vista del personaje: Julio Cortázar.

Cuando Cortázar repudia al molesto intermediario tradicional es porque «le irrita» que los personajes tengan «que quedarse como al margen, mientras el narrador explica por su cuenta (aunque esa cuenta sea la mera explicación y no suponga interferencia demiúrgica) detalles o pasos de una situación a otra»" ${ }^{11}$. Cortázar rechaza al narrador que «modela la arcilla del cuento" desde fuera: "...el narrador pudo haber sido uno de los personajes, es decir que la situación narrativa en sí debe nacer y darse dentro de la esfera, trabajando del interior al exterior, sin que los límites del relato se vean trazados como quien modela una esfera de arcilla» ${ }^{12}$. Así, en muchos de sus cuentos el propio personaje nos habla directamente desde dentro de la historia: bien en primera persona del singular (el caso más corriente); bien en primera del plural, como ocurre con la voz de un personaje perteneciente a una colectividad que recoge las hojas secas en la vispera de difuntos ( legítimo orgullo" ${ }^{13}$; bien en segunda persona (como en $\mathrm{El} \mathrm{rio}^{14}$. De manera que el cuento va adquiriendo las formas de monólogo, recuerdos, diario, forma epistolar, etc... Todos éstos son casos claros de narración homodiegética, de narración trabajada «del interior al exterior», y muy abundantes en la producción de este autor.

Ahora bien, cuando Cortázar utiliza la tercera persona también va a limitar la voz a las vivencias del personaje. En el apartado siguiente trataremos de poner de manifiesto, mediante el análisis de esta modalidad narrativa, esa equivalencia antes anunciada entre la primera persona, y la tercera desde la focalización interna.

\section{LA TERCERA PERSONA PARA LA FOCALIZACIÓN INTERNA}

En los relatos narrados por el propio personaje focalización y voz coinciden, y la segunda se limita a reproducir únicamente lo que aquél puede

"Ver «Del cuento breve y sus alrededores", en Último round, Madrid, Siglo XXI, 4." ed., 1974, Tomo 1, pp. 64-65.

12 Ibidem, p. 60.

13 En Los relatos, 1. Ritos, pp. 41-47.

${ }^{14}$ En Los relatos, 2. Juegos, pp. 37-40. 
percibir de.la historia: todo cuanto desaparece del campo de focalización del personaje, desaparece del discurso. Un magnífico ejemplo de esta restricción es La jalousie de Robbe-Grillet. Del marido-narrador desconocemos su nombre y qué aspecto tiene; lo que él no observa queda oculto para el lector; cuando el sistema de celosías de la casa le impide espiar a la mujer (A...) nos quedamos sin información; desaparecen, como consecuencia, interpretaciones, generalizaciones y valoraciones extradiegéticas; desaparece la manipulación temporal y espacial de un narrador externo y poderoso; el texto se llena de frases dubitativas... La voz del personaje-narrador, en resumen, es limitada porque la focalización lo es.

Pero este mismo fenómeno sucede cuando la voz no es del personaje, siempre que la narración responda a un punto de vista interno. En El viejo y el mar de Hemingway, el agente lingüistico del discurso es diferente del personaje en cuanto a la voz, pero se ciñe al personaje en cuanto a la percepción de acontecimientos. Oscar Tacca, en Las voces de la novela, hace la siguiente precisión acerca de la novela de Hemingway: «...la tercera persona del protagonista no es más que un calco de su visión absolutamente personal: la novela podría ser reescrita en primera persona sin que la merma (desde el punto de vista lógico, naturalmente) fuese apenas perceptible ${ }^{15}$. No observa Tacca, al centrarse en las personas gramaticales exclusivamente, que se encuentra ante un caso de focalización interna y narrador heterodiegético. Este narrador, en el relato, traduce únicamente aquellos datos que le proporciona el focalizador. La aventura de Santiago, el viejo, en el mar está limitada a lo que el personaje ve, siente, percibe. El agente lingüístico del discurso es efectivamente externo, pero la historia tiene el efecto de estar contada por quien aparece implicado en ella, a pesar de esa voz externa.

Los cuentos de Cortázar narrados en tercera persona presentan esta misma fórmula: aunque estamos ante historias narradas por un agente lingüístico externo, lo que prima es el ángulo de percepción interna. Son relatos que parecen estar narrados por el propio personaje, porque si bien la historia se elabora utilizando la voz de un narrador no implicado en ella (mediante la tercera persona) sólo encontramos en el cuento los datos derivados de la percepción del personaje observador. Por lo tanto, ante la apariencia de un narrador que, debido a esa voz externa, va a manejar los hilos de una historia desde fuera, el lector encuentra en el discurso la limitación propia de un narrador que, debido a la perspectiva interna, va tejiéndolos desde dentro. Estamos ante un tipo de relato donde sólo conocemos los acontecimientos según la versión que de ellos tiene el personaje seleccionado para enfocar la historia: es el engaño de la tercera persona. La voz del narrador

${ }^{15}$ Óscar Tacca, Las voces de la novela, Madrid, Gredos, 1973, p. 24. 
queda atrapada en la historia, por la restricción del punto de vista, como si el relato estuviera construido en primera persona.

En Del cuento breve y sus alrededores recuerda Cortázar un hecho acerca de sus narraciones en primera y tercera persona. Dice así: «Hace muchos años, en Buenos Aires, Ana María Barrenechea me reprochó amistosamente un exceso en el uso de la primera persona, creo que con referencia a los relatos de Las armas secretas, aunque quizá se trataba de los de Final de juego. Cuando le señalé que había varios en tercera persona, insistió en que no era así y tuve que probárselo libro en mano. Llegamos a la hipótesis de que quizá la tercera actuaba como una primera persona disfrazada, y que por eso la memoria tendía a homogeneizar monótonamente la serie de relatos del libron" ${ }^{16}$.

Esta hipótesis que plantea Cortázar es la que aplica a los cuentos elaborados mediante una voz externa en tercera persona. Si el lector, ante este tipo de narraciones, tiene la sensación de «estar oyendo» al personaje, si la historia se nos ofrece desde dentro a pesar de la voz de un sujeto no implicado en ella, es debido a que en el texto importa el resultado de la instancia narrativa completa, focalización y voz no la mera transmisión verbal de acontecimientos. Como en los cuentos narrados por el propio personaje, la voz queda supeditada a reproducir únicamente lo que la focalización permite.

El resultado final es el siguiente: cuando la focalización es interna y limitada, la voz es limitada tanto para un narrador homodiegético como para uno heterodiegético. Puede hablarse, en ambos casos, de un narrador integrado en la historia, del "narrador dramatizado» de Lubbock ${ }^{17}$. Podemos también decir que, en cuanto a la función narrativa, desaparece la frontera entre el relato en primera persona y el relato en tercera desde la focalización interna. En ambos casos, el objeto de la narración se ofrece desde dentro, desde la historia misma.

Tango de vuelta comienza con un personaje absolutamente periférico que tuvo un breve contacto con el final de la historia de Matilde y Milo (personajes centrales del cuento) y que, sin embargo, nos va a narrar completa. Dicho personaje la reconstruye, desde el principio, mediante los pocos datos que conoce por la criada de Matilde (Flora) y los que él mismo añade de su imaginación.

«Uno se va contando despacito las cosas, imaginándolas al principio a base de Flora o una puerta que se abre $o$ un chico que grita,

16 Oscar Tacca, Las voces..., op. cit., p. 64.

17 Percy Lubbock, op. cit., p. 116. 
después esa necesidad barroca de la inteligencia que la lleva a rellenar cualquier hueco hasta completar su perfecta telaraña y pasar a algo nuevo»" ${ }^{18}$.

El narrador primero ha creado un segundo narrador para el principio y el final del cuento: un personaje al que le gusta escribir y que, por ello, va a reconstruir la historia de Matilde y Milo tras la muerte de ambos. Este segundo narrador, no implicado en la historia central del cuento, va a reinventarla. Estamos frente a un omnisciente que sabe (imagina) la llegada de Emilio Díaz (Milo) a Ezeiza, conoce sus recorridos «por barrios y cafés y amigos de otros tiempos», su manera de vestir, de andar, su llegada frente a la casa de Matilde para iniciar el asedio, la venganza que terminará en tragedia...

Pero este personaje-narrador que reinventa la historia, ni va a ser tan ajeno ni tan omnisciente. Porque la verdadera historia de Matilde y Milo, que es el cuento, queda limitada al enfoque de la mujer (y la tercera persona, como consecuencia, también es limitada) a las pocas líneas de empezar el relato:

«Matilde lo vio por primera vez - por esta nueva primera vez-desde la ventana del dormitorio en los altos. Flora andaba de compras y se había llevado a Carlitos para que no lloriqueara de aburrimiento a la hora de la siesta, hacia el calor espeso de enero y Matilde buscaba aire en la ventana... "Milo", pensó, si eso era pensar, ese instantáneo vómito del tiempo y de imágenes. «Es Milo». Cuando fue capaz de asomarse desde otra ventana ya no había nadie en la esquina de enfrente, dos chicos venían a lo lejos jugando con un perro negro. "Me ha visto", pensó Matilde. Si era él la había visto, estaba ahí para verla, estaba ahí y no en cualquier otra esquina, contra cualquier otro árbol. Claro que la habia visto porque si estaba ahí era porque sabía dónde quedaba la casa. Y que se hubiera ido en el instante de ser reconocido, de verla retroceder tapándose la boca, era todavía peor, la esquina se llenaba de un vacio donde la duda no servia de nada, donde todo era certeza y amenaza...."19.

Mediante esta óptica, mediante las sensaciones de Matilde, conoce el

18 "Tango de vuelta», en Queremos tanto a Glenda, Madrid, Alfaguara, 1981, p. 83.

19 Ibidem, pp. 85-87. 
lector la persecución que la mujer siente desde la primera vez que, asomada a la ventana, da contra la imagen de Milo parado en la esquina. El punto de vista se ha trasladado por completo al centro de la historia, que es Matilde; la tercera persona actúa sólo "como una primera disfrazada" porque la focalización tiene primacía sobre la voz en cuanto a la vivencia de la historia y al balance de datos que de ella obtenemos.

El autor de este tipo de textos elige focalización y voz diferentes, pero no divergentes puesto que la segunda queda supeditada a las limitaciones de la primera. Narrador y focalizador no confluyen formalmente en una misma instancia personal, pero el efecto de la narración como resultado definitivo es el de la confluencia. Teniendo en cuenta que narración es el resultado de focalización y voz, este tipo de relato supone la narración con el personaje puesto que en ese resultado la voz no va más allá de la focalización interna, se ajusta a ésta con todas las restricciones que conlleva la elección.

Gracias a este fenómeno de supeditación de la voz al foco de la narración, el distanciamiento entre sujeto hablante e historia es mínimo. Como en los relatos en primera persona, estamos en el extremo opuesto al de un narrador externo y omnisciente. A su vez, la desaparición del distanciamiento entre narrador e historia produce la desaparición del distanciamiento entre lector e historia: el lector, en este tipo de narraciones, queda también trasladado al centro de la esfera del cuento. El fenómeno es el mismo que en la narración elaborada mediante la voz del personaje: lo narrado se presenta ante el lector como algo más humano, más verosímil; el lector se halla instalado frente a una historia vivida en ese momento por el personaje. La distancia entre historia y lector es mínima porque el narrador se limita a ser mero informador de los datos que el personaje conoce y puede informar a medida que los va viviendo (en el apartado siguiente veremos, a este respecto, las lagunas de información en la historia). De este modo aumenta el efecto de mímesis en este tipo de relato, como sucede en los de primera persona donde la sensación mimética se produce, como afirma Genette, gracias a la máxima información para un mínimo de informador ${ }^{20}$.

Bestiario presenta la técnica de focalización interna y tercera persona, con sus resultados en el discurso, desde el principio. Lo que oímos es la voz del narrador metida en la conciencia de Isabel, la niña: nos encontramos siempre donde está la niña, y los acontecimientos del relato son contemplados con la fuerza del punto de vista de la infancia; así, aparece el asombro, la atracción por los objetos, gestos, situaciones... Y no se trata del asombro ante lo verdaderamente extraordinario (la presencia de un tigre en la casa es tomada con normalidad por la niña), sino el asombro y la atrac-

${ }^{20}$ Ver GenETTE, Figures III, cit., acerca de la distancia narrativa, pp. 184-186. 
ción por detalles cotidianos que se convierten en extraordinarios gracias a la mirada fascinada de la infancia. Puede servir de ejemplo la comida que Isabel describe a su madre en una carta:

"Querida mamá tomo la pluma para - Comían en el comedor de cristales, donde se estaba más fresco. El Nene se quejaba a cada momento del calor, Luis no decía nada pero poco a poco se le veía brotar el agua en la frente y la barba. Solamente Rema estaba tranquila, pasaba los platos despacio y siempre como si la comida fuera de cumpleaños, un poco solemne y emocionante. (Isabel aprendía en secreto su manera de trinchar, de dirigir a las sirvientitas.) Luis casi siempre leía, los puños en las sienes y el libro apoyado en un sifón. Rema le tocaba el brazo antes de pasarle un plato, y a veces el Nene lo interrumpía y lo llamaba filósofo. A Isabel le dolia que Luis fuera filósofo, no por eso sino por el Nene, porque entonces el Nene tenía pretexto para burlarse y decirselo.

Comían asi: Luis en la cabecera, Rema y Nino de un lado, el Nene e Isabel del otro, de manera que había un grande en la punta y a los lados un chico y un grande. Cuando Nino quería decirle algo de veras le daba con el zapato en la canilla. Una vez Isabel gritó y el Nene se puso furioso y le dijo malcriada. Rema se quedó mirándola, hasta que Isabel se consoló en su mirada y la sopa juliana $)^{21}$.

En la carta se abandonan muy pronto las palabras de la niña para pasar a la tercera persona. Mediante el indirecto libre (Isabel decía a su madre que "comian en el comedor de cristales...») el narrador recoge en el texto la ambigüedad que, como dice Genette al comentar este estilo, «lui permet de faire parler à son propre discours, sans tout à fait le compromettre ni tout à fait l'innocenter, cet idiome à la fois écoeurant et fascinant qu'est le langage de l'autre ${ }^{22}$. El indirecto libre, muy abundante en la modalidad de narración que estamos analizando, no es sino un caso extremo de fenómeno que nos ocupa: la primacía de la percepción interna frente a la voz externa. La fuerza de la percepción llega en muchos momentos a eliminar el plano

21 "Bestiario", en Los relatos, 1. Ritos, cit., p. 19.

${ }^{22}$ GenetTe, op. cit., p. 192. Para la trayectoria de los estilos directo e indirecto libres en el género narrativo, ver: Charles BALLY, "Le style indirecte libre en français maderne I et II", en Germanisch-Romanische Monatsschrift, 4, pp. 549-556 y 597-606; Guillermo Verdin DiAZ, Introducción al estilo indirecto libre en españo, R.F.E., anejo XCI, Madrid, C.S.I.C., 1970; y la visión histórica de Roy PASCAL, The Dual Voice, Manchester, Manchester University Press, 1977, pp. 2-32, y de Volosinov, Marxism and the Philosophy of Language, Londres, Nueva York, Seminar Press, 1973. 
del narrador heterodiegético: en el indirecto libre, este narrador cede su voz definitivamente para fundirla con la del personaje.

La fusión llega a tal extremo en Bestiario que el narrador recoge en el texto el lenguaje infantil en su aspecto temático y expresivo: los detalles que de manera minuciosa impresionan y atraen a la niña; la colocación de los platos convertida en ritual, «como si la comida fuera de cumpleaños, un poco solemne y emocionante»; la forma de trinchar de Rema; la situación de cada personaje en la mesa; el modo de describir propio de un niño, ya que «había un grande en la punta y a los lados un chico y un grande»... El discurso del narrador descubre ahora el discurso propio de la protagonista. Del mismo modo que el relato en primera persona, entendida ésta por Glowin̉ski como relato desde el personaje, el discurso de la niña a través de la tercera persona "relève de la mimésis formalle: c'est une imitation, par le moyen d'une forme donée, d'autres modes de discours littéraires, paralittéraires et extralittéraires, ainsi que, selon une procédé relativement commun, du langage ordinaire ${ }^{23}$. El hablante de este enunciado adopta la visión del mundo de Isabel, y esa visión (con sus valores y emociones) se refleja en el estilo del enunciado mediante una penetración del discurso del personaje en el del narrador: «el enunciado, su estilo y su composición, se determinan por el aspecto temático (de objeto y de sentido) y por el aspecto expresivo, o sea por la actitud valorativa del hablante hacia el momento temático" ${ }^{24}$. Si la expresividad de un enunciado contesta, en mayor o menor medida, es decir «expresa la actitud del hablante hacia los enunciados ajenos $»^{25}$, en el caso que nos ocupa, esa expresividad contesta por completo ${ }^{26}$.

Gracias a esta acertada selección del punto de vista, y porque no importa que la voz sea externa, en este tipo de relato van a fallar los criterios de verosimilitud que dimanan de nuestros códigos culturales, de tal modo que ahora, mediante la focalización seleccionada, se nos hace verosímil lo que en buena lógica sería absurdo. Lo irreal se convierte para el lector en una realidad reconocible (una vez más el concepto de «realismo», en literatura, vuelve a ser problemático e inasible). Este fenómeno puede ejemplificarse magníficamente con La caricia más profunda.

La historia de este cuento describe la sensación que tiene el protagonista de irse hundiendo en la tierra poco a poco, la angustia de irse hundiendo cada día un poco más, hasta desaparecer por completo en una cita con su novia, cuando ya sólo veía «las suelas de los zapatos de ella a tal distancia

\section{p. 500 .}

${ }^{23}$ Michal GlowıǸskı, "Sur le roman à la première persone», Poétique, Paris, Seuil, 1987,

${ }_{24}$ Ver el análisis del enunciado en la comunicación discursiva que hace $\mathrm{M}$. M. BaJtín en su Estética de la creación verbal. México, Siglo XXI, 2." ed., 1985, pp. 256-293.

" Ibidem, p. 282.

${ }^{26}$ Hay sólo dos momentos, pero muy breves, en que asistimos a una narración desde fuera de este personaje; no son, por lo tanto significativos en el relato, sino únicamente excepcionales. 
que ya ni siquiera se notaban las imperfecciones $)^{27}$. Para contar este fenómeno, que no afecta a ningún otro personaje, el narrador se mete tan perfectamente en la sensación del protagonista (aunque utilice la tercera persona) que hace cómplice de dicha sensación al propio lector: no estamos ante un loco; por el contrario, nos sentimos cómplices de la angustia del protagonista, frente a la ceguera de los demás personajes que no son capaces de notar el hundimiento (ni siquiera los más cercanos: la novia o la familia). Más aún, se diria que estamos atrapados como lo está el personaje. Al limitarnos a la visión angosta y subjetiva del protagonista, el relato consigue que adoptemos, como lectores, esa misma visión.

Una historia irreal (en el sentido de su imposibilidad de realización en el universo no ficticio) se convierte en verosímil mediante la selección del punto de vista desde el personaje, a pesar de la voz del narrador. Lo que en buena lógica sería absurdo o propio de una mente enferma, se hace posible para el lector, que no puede disociarse de la situación. Un texto con un grado de ficción máximo, gracias a la selección del punto de vista, pasa a ser absolutamente verosímil. La ilusión de mímesis se realiza, como ya hemos indicado, gracias a una voz que permite trasmitir la historia sin filtro, porque recoge únicamente lo que le dicta la focalización del personaje.

García Berrio comenta el concepto de skaz (de Viktor Vinogradov y Eikhenbaum) como (suma de procedimientos literarios derivados de concebir al narrador en su función de «mediador» entre autor y público. Su finalidad es reforzar la ilusión de la verosimilitud de la mimesis literaria. Los procedimientos básicos para conseguirla: la reproducción de los módulos fonéticos, gramaticales y léxicos del lenguaje hablado y la distorsión continuada de la óptica narrativa, el punto de vista y la voz del narrador ${ }^{28}$. En La caricia más profunda esta finalidad del skaz se lleva a sus últimas consecuencias: el punto de vista, «anulando» a la voz externa a pesar de su presencia en el texto, es aquí el procedimiento básico para conseguir dicha finalidad. El punto de vísta ${ }^{29}$ es el factor que dirige la narración, quien p. 25.

${ }^{27}$ "La caricia más profunda", en Los Relatos, 3. Pasajes, Madrid, Alianza, 4." ed., 1983,

${ }^{28}$ A. García Berrio, Significado actual del formalismo ruso, Barcelona, Planeta, 1973, p. 254 .

${ }^{29}$ Como se ha podido observar, utilizamos indistintamente los términos focalización, punto de vista o percepción para el mismo concepto. Tal vez el más amplio y completo sea, no obstante, el de percepción, puesto que no se limita exclusivamente, como dice Jaap LiNTVELT, «au centre d'orientation visuel c'est-à-dire à la question de savoir qui 'voit', mais implique aussi le centre d'orientation auditif, tactile, gustatif et olfactif. Comme la perception du monde romanesque se trouve filtrée par l'esprit du centre d'orientation, la perspective narrative est influencée par le psychisme du percepteur". Ver Essai de typologie narrative. Le "point de vue", Paris, Librairie José Corti, 1981, p. 42. Queremos respetar, no obstante, el uso de punto de vista y focalización que tanto se ha utilizado y siguen utilizándose en los estudios de narratología; pero lo hacemos, siempre, en el sentido que Lintvelt da al término percepción. 
condiciona la voz del narrador que se convierte en mero registro de percepciones internas.

A veces el discurso, en este tipo de narraciones, delata las restricciones de la focalización interna mediante la aparición de elipsis en el texto. $\mathrm{Si}$ analizamos La noche boca arriba podemos observar que hasta tal extremo ciñe su voz el narrador al punto de vista del personaje que cuando algo desaparece del campo de visión de éste, aquél no puede describirlo y el enunciado refleja una elipsis en el ritmo narrativo:

"Cuando vio que la mujer parada en la esquina se lanzaba a la calzada a pesar de las luces verdes, ya era tarde para las soluciones fáciles. Frenó con el pie y la mano, desviándose a la izquierda; oyó el grito de la mujer, y junto con el choque perdió la visión. Fue como dormirse de golpe.

Volvió bruscamente del desmayo. Cuatro o cinco hombres jóvenes lo estaban sacando de debajo de la moto. Sentía gusto a sal y sangre, le dolía una rodilla, y cuando lo alzaron gritó, porque no podía soportar la presión en el brazo derecho. Voces que no parecían pertenecer a las caras suspendidas sobre él, lo alentaban con bromas y seguridades $)^{30}$.

En este fragmento, por ejemplo, puede verse esta limitación: cuando el personaje tras el accidente de la moto se desmaya, quienes son testigos de la escena (la gente de la calle) desaparecen, y sólo vuelven a la historia al volver en sí el personaje.

En otras ocasiones el discurso delata las limitaciones de la percepción interna mediante la presencia de indeterminados, mediante la inseguridad de la frase:

«Lo llevaron a la sala de radio, y veinte minutos después, con la placa todavia húmeda puesta sobre el pecho como una lápida negra, pasó a la sala de operaciones. Alguien de blanco, alto y delgado, se le acercó y se puso a mirar la radiografia. Manos de mujer le acomodaban la cabeza, sintió que lo pasaban de una camilla a otra. El hombre de blanco se le acercó otra vez, sonriendo, con algo que le brillaba en la mano derecha. Le palmeó la mejilla e hizo una seña a alguien parado atrás $\rangle^{31}$.

30 «La noche boca arriba», en Los relatos, I. Ritos, op. cit., p. 8.

"Ibidem. p. 9. 
"Alguien de blanco", "Manos de mujer», "algo que le brillaba en la mano derecha», «hizo una seña a alguien parado atrás»... Detalles imprecisos en la narración: el lector se queda sin conocer datos que el personaje ( $y$, como consecuencia, el narrador) no puede darnos por no tener acceso a ellos.

Al comentar el punto de vista de este relato, Edelweis Serra dice: «El estilo indirecto de este cuento y algunos indicios y signos de sugestión delatan a un narrador no intruso pero omnisciente, aunque jamás saliéndose de la narración estricta, antes bien inmerso allí para que el relato se manifieste a sí mismo, entregado a la operación de fundir cuanto se cuenta con la expresión de lo contado ${ }^{32}$. Edelweis Serra, aunque habla de un narrador «inmerso» en la historia, lo considera "no intruso pero omnisciente». Esto es totalmente falso puesto que la voz, en este cuento, se deriva de la conciencia del personaje, y el estilo indirecto (la tercera persona) no delata, frente a lo que afirma este autor, a un omnisciente sino a un narrador que asume esa conciencia en todo momento para contarnos, exclusivamente, lo que el personaje percibe con mayor o menor lucidez (en la calle, en la ambulancia, en el hospital), las voces que oye, lo que siente (el ruido de la moto entre sus piernas, la pérdida de conciencia, el dolor), lo que sueña... Para contárnoslo incluso con la pérdida de campo de visión, como se ha podido constatar en los ejemplos arriba citados ${ }^{33}$.

En esta modalidad de narración únicamente tenemos acceso a los datos que el personaje percibe, porque la voz sólo traduce esos datos: una manera de abordar la narración que nos reduce, como lectores, a sentir sólo las impresiones del personaje, a pensar sólo sus pensamientos, porque no existe un intermediario que pueda decirnos lo que aquél no piensa o no siente.

Como caso significativo, dentro de los planteamientos de este apartado, citaremos La barca o Nueva visita a Venecia. Se trata de un relato elaborado en principio con focalización y voz omnisciente, pero que, sin embargo, su autor decidió corregir antes de sacarlo a la luz: introdujo en la historia el punto de vista de uno de los personajes, Dora, a fin de conseguir mayor

${ }^{32}$ Edelweis Serra, Tipología del cuento literario, Madrid, Cupsa Editorial, 1978, p. 93.

${ }^{33}$ Tampoco acierta con el punto de vista, en su comentario sobre este cuento, $S$. Reisz de Rivarola cuando afirma que use pueden distinguir claramente la visión de un focalizador primario objetivo y anónimo que registra las experiencias externas e internas de un motociclista que a raíz de un accidente de tránsito es conducido a un hospital, y la visión del personaje, quien por efecto del fuerte trauma psico-fisico vive buena parte de los sucesos como a través de una bruma, sin capacidad de identificar con precisión la naturaleza y funciones de personas y objetos». La autora ejemplifica ambas focalizaciones con ejemplos en los que sólo aparecen indicadores de una focalización desde el personaje, a pesar de la voz externa. Ver "Voces y conciencias modelizantes en el relato literario-ficcional», en M. A. GARRIDo Gallardo y otros, La crisis de la literariedad, Madrid, Taurus, 1987. 
verosimilitud. Así, junto al primitivo relato, que se respeta, vamos tropezando con las apostillas de Dora que revisa la primera narración. La causa de esta revisión es simplemente que el personaje sabe mejor lo que ocurrió que esa conciencia del omnisciente falseadora de los acontecimientos. El propio autor lo reconoce así en la advertencia preliminar del cuento:

«Si Dora hubiera pensado en Pirandello, desde un principio hubiera venido a buscar al autor para reprocharle su ignorancia o su persistente hipocresia. Pero soy yo quien va ahora hacia ella para que finalmente ponga las cartas boca arriba. Dora no puede saber quién es el autor del relato, y sus críticas se dirigen solamente a lo que en éste sucede visto desde adentro, alli donde ella existe; pero que ese suceder sea un texto y ella un personaje de su escritura no cambian en nada su derecho igualmente textual a rebelarse frente a una crónica que juzga insuficiente $o$ insidiosa.

Asi, la voz de Dora interrumpe hoy de tanto en tanto el texto original que, aparte de correcciones de puro detalle y la eliminación de breves pasajes repetitivos, en el mismo que escribi a mano en la Pensione dei Dogi en 1954. El lector encontrará en él todo lo que me parece malo como escritura y a Dora malo como contenido.... ${ }^{34}$.

De nuevo la preocupación consciente de Cortázar para abordar el relato desde el personaje, frente al primitivo texto elaborado desde la «ignorancia» o la «hipocresía» del omnisciente. Cortázar, en su función de narrador, pierde premeditadamente el privilegio de moverse más allá de "la esfera» del relato: «... cuando escribo un cuento busco instintivamente que sea de alguna manera ajeno a mí en tanto demiurgo, que eche a vivir con una vida independiente, y que el lector tenga o pueda tener la sensación de que en cierto modo está leyendo algo que ha nacido por sí mismo, en sí mismo y hasta sí mismo, en todo caso con la mediación pero jamás la presencia manifiesta del demiurgo" ${ }^{35}$.

Otro caso significativo, debido al uso de las personas gramaticales, es el cuento "Usted se tendió a tu lado". El narrador recoge los pensamientos, voces, sensaciones de Denise (la madre) y de Roberto (el hijo). Cuando se refiere a ella utiliza la forma "usted» como variante de cortesía; cuando es a Roberto a quien menciona, lo hace mediante el «tú» o "vos» como variante familiar de confianza (el voseo americano con sus correspondientes casos

34 "La barca o Nueva visita a Venecia", en Alguien que anda por ahi, Madrid, Alfaguara, 3." ed., 1984, p. 110.

3 CORTÁzAR, «Del cuento breve y sus alrededores», op. cil., pp. 64-65. 
complementarios y formas verbales). Encontramos, de este modo, la segunda persona en vez de la tercera, pero con la misma función que hemos delimitado para esta última. La cuestión no es qué formas gramaticales se utilizan sino la función que éstas tienen, la actitud narrativa, como dice Genette: «Le choix du romancier n'est pas entre deux formes grammaticales mais entre deux attitudes narratives (dont les formes grammaticales no sont qu'une conséquence mécanique)»" ${ }^{36}$. Aquí, para la segunda persona como para la tercera en los casos anteriores, se ha elegido de nuevo la restricción a las percepciones de los personajes; es la actitud narrativa del relato:

«Usted se tendió a su lado y vos te enderezaste para buscar el paquete de cigarrillos y el encendedor.

- No, gracias, todavía no - dijo usted sacando los anteojos de sol del bolso que le habías cuidado mientras Denise se cambiaba.

- ¿Querés que te vaya a buscar un whisky? -le preguntaste» ${ }^{37}$.

\section{LAS LAGUNAS DE INFORMACIÓN EN EL TEXTO}

Abordaremos a continuación, y ampliaremos, la idea que propone Genette de paralipse como "retention d'une information logiquement entraînée par le type adopté $\aleph^{38}$. Para ello veamos otra característica común a los relatos en primera persona, y en tercera desde la focalización interna: la presencia de veladuras, de datos oscuros para el lector en el texto, la abundancia de lagunas de información que se derivan del punto de vista limitado al personaje.

Con la narración desde la perspectiva interna, a pesar de la tercera persona, nos hallamos en el extremo opuesto al de un narrador patente, manipulador de la historia. No sólo la ausencia de metalepsis es la tónica del discurso, en los textos que nos ocupan, sino el polo opuesto a toda retórica omnisciente. Ahora carecemos de la sobre-información que un narradorfocalizador externo puede ofrecer; pero más aún, carecemos de la propia información del personaje (que el narrador no suplirá con su voz). Las lagunas de información son otra de las características, y de las consecuencias de la focalización interna, en el tipo de relato que analizamos.

36 GenetTe, Figures III, cit., p. 191.

37 "Usted se tendió a tu lado", en Alguien que anda por ahi, cit., p. 62.

3* GenetTe, Nouveau discours du récit, Paris, Seuil, 1983, p. 44. 
Al quedar la narración ceñida a las percepciones del personaje, pueden darse dos tipos de paralipse:

a) El personaje desconoce, o no comprende, elementos de la historia $y$, en consecuencia, no tiene capacidad para ofrecerlos en el relato.

b) El personaje conoce algunos datos que, sin embargo, calla porque no tiene en cuenta al lector dado que se limita a vivir la historia, no es un intermediario capaz de aclarar situaciones.

Un ejemplo donde se encuentran ambas posibilidades es Bestiario ${ }^{39}$ :

a) Isabel no puede hablarnos, porque escapa a su capacidad debido a sus pocos años (que tampoco sabremos con precisión), del problema del incesto que hay en la casa, de la relación exacta entre Rema y el Nene. La niña sólo capta detalles aislados que acumula en su conciencia con minuciosidad (y le llevan a salvar a Rema de algo que sin embargo desconoce), detalles como la agresividad y el poder del Nene frente a la ternura y debilidad de Rema, las palabras de Luis referidas al Nene «Es un miserable, un miserable», la imagen de «la boca dura y hermosa» del Nene «de labios rojísimos", su sonrisa, el llanto de Rema... El lector, sin embargo, sabe más que la propia Isabel, pero no porque el narrador aclare, precise los hechos sino porque el lector, con su edad superior a la de la niña, los deduce. Isabel se extraña ante la confusión del Nene (que no es tal confusión) al tomar los dedos de Rema en lugar de la taza de café; el lector sonríe comprendiendo que la niña es quien confunde el suceso de la taza en su interpretación. Donde Isabel sólo ve un gesto de agresividad, el lector ve uno erótico.

El narrador muestra al lector los acontecimientos a través de la limitada visión de una niña. Pero el lector interpreta la información que recibe de manera distinta. Según Genette el tipo clásico de paralipse es «dans le code de la focalisation interne, l'omission de telle action ou pensée importante du héros focal, que ni le héros ni le narrateur choisit de dissimuler au lecteur ${ }^{40}$. Pero en el caso que estamos analizando se da un grado más de paralipse: la falta de información en el discurso es debida a la falta de información del propio personaje, que sí ignora acciones o pensamientos de la historia que el narrador, al ceñirse estrictamente a la visión interna, no puede traducir. Como en el relato en primera persona, el lector en estas

${ }^{19}$ "Bestiario», en Los relatos, 1. Ritos, op. cit., pp. 16-31.

40 GENETTE, Figures III, op. cit., p. 212. 
narraciones «est condamné à une incertitude tres particulière quant à la valeur d'information de la phrase en question. Il ne peut pas en référer à l'autorité d'un narrateur, car lorsqu'une histoire est racontée à la premiére personne le narrateur se trouve sur le même plan que tous les autres personnages, simple mortel comme eux et donc, comme eux fallible ${ }^{4 l}$. Aunque el narrador en tercera persona no sea un personaje, funciona con las mismas limitaciones de un personaje de modo que la tercera persona verbal es equivalente a la primera en cuanto a la información que de la historia pueden ambas ofrecer.

La limitación del punto de vista la completa el lector con su madurez. A la focalización del personaje, en esta historia, se le añade la interpretación del lector. La instancia narrativa es ahora el resultado de tres categorias: focalización del personaje + voz del narrador + focalización del lector. $Y$ denominamos focalización del lector a esa interpretación porque el lector percibe lo que está ocurriendo en la historia, mientras al personaje, por su corta edad, no le está permitido percibirlo. El lector añade, en estos casos, parte de la focalización como cómplice de la lectura, gracias a los indicios (según la concepción de Barthes ${ }^{42}$ ), como exceso de información, que aparecen implícitamente en el texto. Hay por lo tanto una tensión entre desinformación de la historia (paralipse, por desinformación del personaje) e información implicita (interpretación del lector, focalización, quien por madurez traduce indicios no comprensibles para el personaje).

b) La segunda posibilidad de paralipse aparece también en Bestiario. El personaje conoce datos que, por innecesarios, no ofrece al lector a través de la tercera persona del texto. En este caso hay omisión de pensamientos que el personaje no puede ignorar.

Un focalizador-narrador omnisciente nos explicaría las relaciones familiares (en Los Horneros) entre Luis, el Nene, Rema y Nino. Pero la conciencia de Isabel, desde la que se ofrece la historia, está puesta en los acontecimientos que suceden en una familia que ya conoce de antemano: ipara qué precisar en el cuento el parentesco existente entre los miembros de esa familia? La consecuencia es la paralipse: una lectura que no sea minuciosamente atenta y analítica no nos permite asegurar si Rema, Luis y el Nene son hermanos, si Rema y Luis están casados y el Nene es hermano de uno de ellos. Será preciso acudir a pequeños detalles entresacados de esa lectura minuciosa, para conocer un parentesco que el narrador no aclara por su fidelidad al punto de vista del personaje. No se narra la historia con esa claridad con que Cortázar puede hablar del parentesco fuera ya del cuento, fuera ya del punto de vista de la niña. En Ultimo round, por ejemplo, dice

41 Michael GlowiṄskı, op. cit., p. 500.

${ }^{42}$ Roland Barthes, Le degré zéro de l'écriture, Paris, Gonthier, 1970, pp. 107 y sig. 
el autor refiriéndose a Luis: «... el recuerdo de un tigre y un hermano deshecho a zarpazos [el Nene] pudo más que la improbable felicidad de Rema ${ }^{43}$. Además, ¿el Nene termina deshecho a zarpazos? En la mente de Cortázar-autor sí; pero en la del lector, que sólo aborda el cuento, queda un final abierto a la duda de hasta dónde pudo llegar el tigre, ya que lo único que se narra es cómo toda la familia se lanza hacia el despacho al primer alarido del Nene.

Los finales abiertos de algunos relatos no son sino lagunas de información relacionadas con la restricción del punto de vista. Por ejemplo, en «Bestiario» el narrador detiene las vivencias de Isabel en el momento de máxima importancia para la niña, en el momento que se cierra para ella la historia que le ha venido preocupando en Los Horneros. Y ese momento es el de su intervención para librar a Rema del Nene, y el de su llanto contra el agradecimiento de Rema. Aunque sus vacaciones de verano no hayan acabado, aunque no sepamos si el Nene "termina deshecho a zarpazos", el narrador no tiene opción a ofrecer más desde el punto de vista de Isabel al que se ha ceñido durante toda la historia. En Verano ${ }^{44}$ la puerta del salón aparece abierta, tras el pánico de un caballo furioso que en la noche anterior ha rondado la casa: ¿abrió tal vez la niña esa puerta para facilitar la entrada a ese caballo? ¿entró o no el animal? Efectivamente, el elemento mágico del caballo, su coincidencia con la llegada de la niña a la casa, queda incrustado en la realidad del cuento. Pero los personajes, desde quienes se ha decidido narrar, desconocen muchos datos y, como consecuencia, el final es oscuro, queda abierto únicamente a la sospecha.

A menudo la oscuridad del relato es debida al uso constante de anacronías que se derivan, no de la voluntad narrativa de ofuscar al lector, sino del ajuste discursivo a la focalización interna. El relato desde el personaje facilita la anacronía. Por medio de retrospecciones internas, cuyo contenido coincide en parte con el de la fábula primordial, se compensan en el relato las lagunas de la historia ${ }^{45}$. En Cartas a mamá ${ }^{46}$ una historia oscura e incompleta, en principio y como derivación de la vivencia del personaje, presenta una serie de retrospecciones también incompletas ${ }^{47}$ que el personaje no necesita completar para el lector, frente a lo que ocurriria en el caso de un narrador omnisciente. Es el lector quien necesita ir colocando las piezas que le faltan, a medida que la conciencia del personaje le va entregando de

4.3 CORTÁzar, Último round, op, cit., p. 122.

44 "Verano", en Los relatos, 2. Juegos, Madrid, Alianza editorial, 4." ed., 1982, pp. 90-99.

4.5 Mieke BAL, Teoria de la narrativa (Una introducción a la narratologia). Madrid, Cátedra, 1985, pp. 59-76.

46 "Cartas de mamá", en Los relatos, 1. Ritos, op. cit., pp. 222-240.

${ }^{47}$ Mieke Bal considera la retrospección incompleta «si después de un (breve) lapso se hace un nuevo salto adelante». Ver Teoria de la narrativa (Una introducción a la narratología), op. cit., p. 69. 
forma desordenada dichas piezas; y sólo a medida que encajan unas y otras va comprendiendo el lector la historia. Por ejemplo, Nico, citado en una carta de mamá por confusión, preocupa a Luis:

«Sacó otra vez la carta del sobre, sin ilusiones: el párrafo estaba ahí, bien claro. Era perfectamente absurdo pero estaba ahí. Su primera reacción, después de la sorpresa, el golpe en plena nuca, era como siempre de defensa. Laura no debía leer la carta de mamá. Por más ridículo que fuese el error, la confusión de nombres (mamá habría querido escribir "Victor" y había puesto "Nico"), de todos modos Laura se afligiria, sería estúpido. De cuando en cuando se pierden cartas; ojalá ésta se hubiera ido al fondo del mar. Ahora tendría que tirarla al water de la oficina...»

Esta información aparece en la página 224. ¿Por qué esta preocupación de Luis le lleva a ocultar la carta a Laura? Nos lo explicaremos cuando aumenten los datos sobre Nico, a cada paso del relato, a medida que los personajes necesiten utilizarlos: Nico había muerto "hacía más de dos años» (información de la página 225); Luis y Laura habian escapado de Paris tras la muerte de Nico, hermano de Luis (más adelante, en página 226); Nico fue antes el novio de Laura (en página 228); sabremos del silencio sobre Nico que, tras todos estos acontecimientos, se estableció entre Luis y Laura, un silencio que se convierte en una especie de complicidad culpable para estos dos personajes...

La oscuridad de datos necesarios para la comprensión de la historia se mantiene durante todo el relato y se va aclarando muy despacio, sólo a medida que avanza la narración de la mano de las vivencias de los personajes y mediante la técnica de la retrospección. Aunque los personajes conocen de antemano todos los elementos oscuros para el lector, no son quienes deben explicarlos: se limitan a vivir la historia. Y el narrador, con su elección de enfoque limitado, hará lo mismo que ellos.

Es frecuente que estos relatos (como es frecuente cuando narra el propio personaje focalizador) comiencen in media res. A veces, las retrospecciones cubren esa parte omitida, al principio, para facilitar la comprensión de la historia; pero en otras ocasiones el lector se queda únicamente con las lagunas de información que el narrador por su cuenta no puede compensar, al no poseer una voz liberada de la perspectiva interna.

Otro modo de lograr la confusión en el lector es «usar un observador que él mismo esté confundido» (para Booth es «el modo más efectivo» de ofuscar al lector ${ }^{48}$ ). Esta confusión está destinada, así, a ser tan grande como

4 Wayne C. Booth, La retórica de la ficción, Barcelona, Bosch, 1974, pp. 269 y sig. 
la del personaje. En Segunda vez ${ }^{49}$ hay siempre un narrador que no se molesta en exponer, o no puede hacerlo, qué ocurre con exactitud en esa oficina montada para la desaparición de ciertas personas, cuáles son éstas, qué criterios existen para su selección: ni el personaje que trabaja en dicha oficina (e inicia y termina el cuento con su propia voz) aclara los detalles y la finalidad de todo este proceso, ni la muchacha seleccionada en la historia para efectuar la desaparición puede comentar qué ocurre, porque ella misma lo desconoce. De nuevo la paralipse aparece en el texto, como falta de información en el discurso por falta de información en el propio personaje.

\section{CONCLUSIONES}

1. En los relatos narrados en tercera persona desde la focalización interna, si bien la historia se construye utilizando la voz de un narrador no implicado en ella, sólo encontramos en el discurso los datos derivados de la percepción del personaje. La voz no va más allá de la focalización, se ajusta a ésta con todas las restricciones y consecuencias que conlleva dicha elección.

2. Si bien focalizador y narrador no confluyen en una misma instancia personal, el efecto de la narración como resultado definitivo es el de la confluencia. El carácter comunicativo que conlleva el punto de vista desde el personaje (las limitaciones de este carácter) afecta a la naturaleza verbal del texto. Así, el análisis de la tercera persona desde la focalización interna nos lleva a localizar una serie de manifestaciones, en el discurso, idénticas a las que presentan las narraciones en primera persona:

3. La ausencia de juicios (como explicaciones que se asientan sobre una base moral externa al relato), generalizaciones (comparaciones de acontecimientos existentes en la historia con acontecimientos reales del universo no fabulado) e interpretaciones (como valoraciones acerca de algo, en términos de la historia misma, $\sin$ ir fuera de ella) es propia de este tipo de

49 «Segunda vez», en Alguien que anda por ahi, op. cit., pp. 47-57. 
narración. Como en los relatos construidos en primera persona, no hay en la tercera desde la focalización interna una voz que mediatice el discurso.

4. A menudo, el discurso delata también las restricciones de la focalización interna mediante la aparición de elipsis en el ritmo narrativo, así como la presencia de indeterminados en la elaboración del texto.

5. La paralipse es otra de las caracteristicas propias de estos relatos. La paralipse aparece como retención de información por: desconocimiento o incomprensión de elementos de la historia por parte del personaje; por omisión de pensamientos que el personaje no puede ignorar pero omitirá como innecesarios. La tercera persona, al ajustarse a la focalización interna, no suple en modo alguno estas retenciones de información.

6. Los finales abiertos y los comienzos in media res, en muchas ocasiones son un caso más de paralipse, una consecuencia más de la restricción del punto de vista interno. Unos y otros son lagunas de información que el narrador no puede compensar por su cuenta, al no poseer una voz liberada de la perspectiva interna.

7. La presencia de anacronías es también una derivación, no de la voluntad narrativa de confundir al lector, sino del ajuste discursivo a la focalización del personaje.

8. La desaparición del distanciamiento entre sujeto hablante e historia es otra de las características de la narración que nos ocupa. Como en los relatos en primera persona, nos encontramos en el extremo opuesto al de un narrador externo y omnisciente.

9. Esa desaparición del distanciamiento entre narrador e historia lleva consigo la desaparición del distanciamiento entre lector e historia. El efecto de mímesis aumenta en este tipo de relatos, como sucede en los narrados por el propio personaje, hasta tal punto que textos con un grado de ficción máximo pasan a ser absolutamente verosímiles para el lector. La acción desprovista de un marco espacial que permita vincular al relato con la rea- 
lidad, produce (debido a la focalización seleccionada) una total sensación de mímesis de la realidad.

10. La voz en tercera persona, cuando queda supeditada a la perspectiva del personaje, es sólo aparentemente ajena a la historia. El narrador heterodiegético queda sometido a la focalización, que toma prioridad en el texto. Los relatos así concebidos se elaboran "desde dentro", como se elaboran las narraciones en primera persona.

11. Podemos afirmar, como consecuencia de este análisis, que cuando la focalización es interna y limitada, la voz es limitada tanto para un narrador homodiegético como para uno heterodiegético. Así, en cuanto a la función narrativa, la narración en tercera persona desde la focalización interna es equivalente a la narración en primera persona. 